\title{
Heuristic and systematic processing differentially influence the effects of scientific consensus messaging on perceived scientific consensus
}

\author{
Keiichi Kobayashi ${ }^{1}$ (D) \\ Accepted: 11 December 2020/Published online: 5 January 2021 \\ (C) The Author(s) 2021
}

\begin{abstract}
This study investigated the impact of scientific consensus messaging on perceived scientific consensus in terms of heuristic and systematic processing. Japanese undergraduates $(N=226)$ received a message indicating relatively moderate and high levels of scientific consensus on the safety of foods grown with pesticides and genetically modified (GM) foods. Participants in the presentation-style evaluation condition evaluated the style and manner of providing the message and thereby were encouraged to heuristically process information about scientific consensus in the message. Participants in the content evaluation condition evaluated the message content and therefore could process the information systematically. After evaluating the message, participants' perceptions of scientific consensus improved. The levels of posteriorly perceived scientific consensus were higher for the presentation-style evaluation condition than for the content evaluation condition. Participants' initial beliefs about the GM-food safety predicted their posterior perceptions of scientific consensus for the content evaluation condition but not for the presentation-style evaluation condition. These results suggest that the heuristic and systematic processing of scientific consensus information differentially influence the impact of scientific consensus messaging.
\end{abstract}

Keywords Perceived scientific consensus - Scientific consensus messaging $\cdot$ Heuristic processing $\cdot$ Systematic processing Science communication

\section{Introduction}

People often misperceive the actual levels of consensus among scientists on scientific issues, including humancaused climate change and the safety of genetically modified (GM) foods (e.g., Pew Research Center, 2015). This poses a challenging problem for science communication, given that individuals' perceptions of scientific consensus are a determinant of their issue-relevant beliefs and attitudes (e.g., Ding, Maibach, Zhao, Roser-Renouf, \& Leiserowitz, 2011; Lewandowsky, Gignac, \& Vaughan, 2013; Van der Linden, Leiserowitz, Feinberg, \& Maibach, 2015; Van der Linden, Leiserowitz, \& Maibach, 2019).

The simplest method for solving the problem of the public's misperception is to inform individuals about the actual scientific consensus by sending a straightforward message,

Keiichi Kobayashi

kobayashi.keiichi@shizuoka.ac.jp

1 Faculty of Education, Shizuoka University, Shizuoka 422-8529, Japan such as "97\% of climate scientists have concluded that human-caused climate change is happening" (Myers, Maibach, Peters, \& Leiserowitz, 2015, p. 5) and "Did you know? A recent survey shows that $90 \%$ of scientists believe genetically modified foods are safe to eat" (Dixon, 2016, p. 893). Indeed, there is a growing body of evidence that, at least under certain conditions, scientific consensus messaging effectively improves people's perceptions of scientific consensus (e.g., Bolsen \& Druckman, 2018; Dixon, 2016; Goldberg, van der Linden, Ballew, Rosenthal, \& Leiserowitz, 2019; Kerr \& Wilson, 2018; Kobayashi, 2018, 2019; Lewandowsky et al., 2013; Myers et al., 2015; van der Linden et al., 2015, 2019).

Less is known about how individuals process a scientific consensus message, thereby estimating the level of scientific consensus. For example, Dixon (2016) and Goldberg et al. (2019) found that presenting neither mere numerical values (e.g., "90") nor thematically-irrelevant consensus information (e.g., a message stating the level of consensus among dentists on tooth-brushing in the context of the climate-change issues) affected perceived scientific consensus, suggesting that superficial anchoring (Bahník, Englich, \& Strack, 2017) does not 
account for the effectiveness of scientific consensus messaging. The cultural cognition thesis (Kahan, 2015; Kahan, Jenkins-Smith, \& Braman, 2011) contends that people deal with scientific consensus information in defense of their worldviews or cultural identities. However, existing evidence as to this contention is mixed. Some studies showed the defensively-motivated influence of basic attitudes and beliefs on the messaging effects (e.g., Bolsen \& Druckman, 2018; Cook \& Lewandowsky, 2016), whereas other studies did not (e.g., Myers et al., 2015; van der Linden et al., 2019).

Drawing on the heuristic-systematic model (Chaiken, 1980; Chaiken \& Ledgerwood, 2012; Chen \& Chaiken, 1999), the present study addressed the question what psychological mechanism underlies the effectiveness of communicating the level of scientific consensus. More specifically, I examined the impact of scientific consensus messaging on perceived scientific consensus in terms of heuristic and systematic processing.

\section{Heuristic and Systematic Processing}

The heuristic-systematic model (e.g., Chaiken \& Ledgerwood, 2012), which is among the dual-processing models of persuasion (Bohner, Erb, \& Siebler, 2008), proposes that a persuasive message influences recipients' judgment through heuristic and systematic processing. Heuristic processing is to activate and apply cognitive heuristics stored in long-term memory. It requires less cognitive effort and imposes lower cognitive load because only minimal amount of information necessary for judgment, including information serving as a heuristic cue, is collected and used for the processing. On the other hand, owing to its hastiness and shallowness, individuals' judgement is vulnerable to misleading information. Systematic processing, which individuals employ when heuristic processing does not give them judgmental confidence, involves dealing with relevant information in a comprehensive, analytical, and integrative way. Whether individuals successfully engage in this mode of processing depends on their effort and cognitive capacity. Despite its deliberateness and thoughtfulness, systematic processing is not always objective or impartial. When individuals are motivated to be defensive and when their informational resources (e.g., arguments in a persuasive message) for judging accurately are limited, their vested interests, attitudes, or beliefs may bias their judgment. Heuristic and systematic processing can serve to pursue the same goal (e.g., making a valid judgment), but still the two modes of processing may produce different outcomes. For example, prior research has shown that the mere heuristic processing of a persuasive message produces tentative and superficial effects on recipients' beliefs and attitudes, whereas systematic processing produces enduring and substantive effects (Chaiken, 1980; Griffin, Neuwirth, Giese, \& Dunwoody, 2002; Mackie, 1987).
Evidence suggests that when information about group consensus is presented as the main body of a persuasive message, people process the information heuristically in some cases but systematically in others. For example, Giner-Sorolla and Chaiken (1997) found that individuals processed a group consensus message (without arguments) more systematically and defensively when the message was incongruent with their vested interests than when congruent. In a study by Darke et al. (1998), when an issue was low in personal relevance, individuals tended to square their attitudes about the issue with the majority's opinion presented in a message, regardless of the source quality of the message, suggesting that they processed the consensus information heuristically. When the personal relevance of the issue was high, the individuals processed the consensus information systematically and therefore gave more consideration to the source quality. However, previous studies have focused on the processing of information about a level of consensus among non-scientists (e.g., undergraduate students) on a non-scientific issue (e.g., a new requirement for graduation). The role of heuristic and systematic processing in the context of scientific consensus messaging remains open.

\section{Processing of Scientific Consensus Information}

Some researchers posit that ordinary people process a scientific consensus message in the heuristic mode (Ding et al., 2011; Kerr \& Wilson, 2018; Lewandowsky et al., 2013). Put differently, it is assumed that scientific consensus information serves as a cue to activate the consensus heuristic (e.g., "the majority's opinion is correct") and the expert heuristic (e.g., "expert opinion is correct"), both of which then affect people's judgment (van der Linden et al., 2019). Consistent with this assumption, Deryugina and Shurchkov (2016) and Harris, Sildmäe, Speekenbrink, and Hahn (2019) suggested that ordinary people's acceptance of a scientific consensus message is not a consequence of careful scrutiny and therefore is superficial. In Harris et al.'s (2019) study, the presentation of information about a high level of scientific consensus increased individuals' perceptions of scientific consensus, whether the information came from a credible source or not. Deryugina and Shurchkov (2016) found that giving individuals a scientific consensus message improved their scientific beliefs briefly, but the messaging effect did not last long.

Still, under certain circumstances, even ordinary people may look at information about scientific consensus critically, with the result that they may reject the information. For instance, Van der Linden, Leiserowitz, Rosenthal, and Maibach (2017) found that forewarning individuals of misinformation about scientific consensus reduced the impact of the misinformation on their perceptions of scientific consensus. In a study by Conway III and Repke (2019), which gave individuals a message stating the actual level of scientific consensus on 
anthropogenic global warming, those who believed more strongly that the scientific consensus had been formed under political pressure were more likely to oppose legislation to mitigate climate change.

In any case, no empirical research has examined the impact of communicating the level of scientific consensus in terms of heuristic and systematic processing. It is too early to infer from the findings of previous studies whether the two modes of processing play a role in producing the observed effects of scientific consensus messaging.

\section{The Present Study}

The present study investigated whether and how the impact of scientific consensus messaging on perceived scientific consensus differs according to how information about scientific consensus in the message is processed. To this end, the manner of dealing with a scientific consensus message was manipulated by assigning participants to one of two conditions: the presentation-style evaluation condition and the content evaluation condition. Participants in the presentation-style evaluation condition received a scientific consensus message and evaluated how well and comprehensibly the message was presented. That is, they were encouraged to direct their cognitive efforts toward evaluating the style and manner of providing the message and thereby shallowly process what was said in the message. Participants in the content evaluation condition evaluated the reliability and importance of the message. They paid attention to the message content and could process it deeply or, of course, shallowly. Based on Martin, Hewstone, and Martin (2007) indicating the connection between the depth and modes of processing, it was expected that evaluating the presentation style and manner would facilitate the heuristic processing of information about scientific consensus in the message. Evaluating the message content would activate participants' preexisting scientific beliefs and allow them to process the scientific consensus information in the systematic mode (if motivated by the activated beliefs) or in the heuristic mode (if not).

On the basis of the above discussion, four hypotheses were proposed. Prior research has shown that scientific consensus messaging is effective in improving individuals' perceptions of scientific consensus. Therefore, it was hypothesized that perceived scientific consensus would be higher after scientific consensus messaging than before (Hypothesis 1). The heuristic-systematic model and previous findings also suggest that individuals are more likely to accept information about group consensus after the information is processed in the heuristic mode than in the systematic mode. When group consensus information to which individuals pay attention is incompatible with their preexisting beliefs, they may be motivated to process the information systematically and defensively. Thus, it was hypothesized that posteriorly perceived scientific consensus (after scientific consensus messaging) would be higher for the presentation-style evaluation condition than for the content evaluation condition (Hypothesis 2) and that preexisting scientific beliefs would predict posteriorly perceived scientific consensus for the content evaluation condition but not for the presentation-style condition (Hypothesis 3). Finally, the existing literature suggests that individuals' acceptance of group consensus information is more superficial and therefore has smaller effects on their issue-relevant beliefs after they process the information heuristically than systematically. Thus, it was hypothesized that posteriorly perceived scientific consensus would more strongly predict posterior scientific beliefs for the content evaluation condition than for the presentation-style evaluation condition (Hypothesis 4).

\section{Method}

\section{Participants}

Participants were 226 undergraduate students (118 females; average age $=18.79$ years, $S D=.84$ ) enrolling in a national university in Japan. All of them were native speakers of Japanese and received extra course credit for their participation. Participants were randomly assigned to the presentationstyle evaluation condition $(n=113)$ or the content evaluation condition $(n=113)$. Sensitivity analyses for key significance tests were conducted using G*Power 3.1.3 (Faul, Erdfelder, Buchner, \& Lang, 2009). The analyses indicated that given the present sample size and $\alpha=.05$, effect sizes of $\boldsymbol{d}=0.17$ (for differences between two dependent means) and $\boldsymbol{f}^{2}=0.03$ (for linear multiple regressions: fixed models, single regression coefficients) would be detectable with $80 \%$ power.

\section{Stimulus}

The safety of foods grown with pesticides and GM foods were adopted as scientific issues. Evidence suggests that Japanese adults underestimate the level of scientific consensus on the safety of GM foods and incline to the belief that both foods grown with pesticides and GM foods are unsafe (Food Safety Commission of Japan, 2015; Kobayashi, 2019). A message about scientific consensus on the safety of foods grown with pesticides and GM foods was presented with pie charts as the results of a (fictitious) survey. The levels of consensus were created using the results of Pew Research Center (2015). The message was as follows: "In 2016, the Science Council of Japan conducted a survey of opinions about the safety of foods, with a random sample of 1,043 scientists. Results indicated that $68 \%$ of the scientists agreed that foods grown with pesticides are safe to eat. Additionally, $88 \%$ of them agreed that genetically modified foods are safe to eat." 


\section{Measures}

Issue Familiarity and Personal Importance Issue familiarity and personal importance were assessed primarily for exploratory purposes because prior findings suggest that these variables may influence the impact of consensus messaging (e.g., Bolsen \& Druckman, 2018; Darke et al., 1998). Participants rated their familiarity with the health risks of foods grown with pesticides and GM foods, using a 7-point Likert-type scale $(1=$ not familiar at all, $7=$ very familiar $)$. They also rated their personal importance of the safety of foods grown with pesticides and GM foods, using a 7-point Likert-type scale $(1=$ not important at all, 7 = very important).

Perceptions of Scientific Consensus Participants estimated the percentages $(0-100 \%)$ of scientists who would agree with the following belief statements: "Foods grown with pesticides (Genetically modified foods) are safe to eat."

Food-Safety Beliefs Participants rated the extent to which they agreed with the following six belief statements concerning the safety of foods grown with pesticides and GM foods, using a 7-point Likert-type scale ( $1=$ strongly disagree, $7=$ strongly agree): "Foods grown with pesticides (Genetically modified foods) are safe for adults to eat," "Foods grown with pesticides (Genetically modified foods) are safe for children to eat," and "Scientific evidence favors the safety of foods grown with pesticides (genetically modified foods)." These ratings were averaged for beliefs about the two issues so that higher scores indicated stronger beliefs (Cronbach's $\alpha \mathrm{s}=.77$ to .86 ).

Reasons for Message Evaluation After participants evaluated the presentation style and manner or the message content, they gave reasons for their evaluation (see below in details). This measure was used to check the validity of the experimental manipulation. Participants' reasons were segmented into sentences, and each sentence was coded as style-based reason, contentbased reason, or other. A style-based reason is a statement that justifies one's judgment by or comments on the style and manner of presenting the survey results (e.g., "The pie charts are effective in making the results understandable"). A content-based reason is a statement that justifies one's judgment by or comments on the message content, including the characteristics of the sample, the questionnaire design, and the survey results (e.g., "I think the survey results are not important because not all of the responding scientists may have been experts on the safety of foods"). Approximately $20 \%$ of the sentences were randomly selected and coded by an independent judge. Interrater reliability (the agreement with the author) was Cohen's $k=.90$. Disagreements were resolved through discussion.

Memory for Scientific Consensus Information Given the memory effects of the depth of processing (e.g., Craik \& Lockhart,
1972), it is possible that the presentation-style versus content evaluation conditions affect the encoding and retention of scientific consensus information rather than the modes of processing. To examine this possibility, memory for the level of scientific consensus presented in the message was assessed. Participants recalled the survey results, that is, the percentages of the responding scientists agreeing with the safety of foods grown with pesticides (68\%) and GM foods (88\%).

\section{Procedure}

The experiment was conducted during a regular class period. Participants reported their issue familiarity, personal importance, estimates of scientific consensus, and food-safety beliefs. Next, they received the scientific consensus message. Using a 7-point Likert-type scale $(1=$ not at all, $7=$ very much so), participants in the presentation-style evaluation condition rated the extent to which the survey results in the message were presented well and comprehensibly. Participants in the content evaluation condition rated the reliability and importance of the survey results. Participants in the two conditions also provided reasons for their ratings. After the message and answer sheets were removed, participants reported their estimates of scientific consensus and food-safety beliefs again and recalled the levels of scientific consensus presented in the message.

\section{Analysis Plan}

Analyses were conducted separately for the safety of foods grown with pesticides and GM foods. To examine Hypothesis 1, mean differences between the initial and posterior estimates of scientific consensus were analyzed using paired $\boldsymbol{t}$-tests. For Hypotheses 2 and 3, multiple regression analyses were conducted on the posterior estimates of scientific consensus. Regression models for testing Hypothesis 2 included evaluation condition (presentation-style $=0$, content $=1$ ) as a predictor and initial food-safety beliefs, initial estimates of scientific consensus, issue familiarity, and personal importance as covariates. Regression models for testing Hypothesis 3 included initial food-safety beliefs, evaluation condition, and their interaction as predictors and initial estimates of scientific consensus, issue familiarity, and personal importance as covariates. The predictors and covariates were mean-centered so that the mean of each variable would be zero. The significant interaction was decomposed by testing the simple slopes defining the effect of initial food-safety beliefs for the presentation-style and content evaluation conditions. To examine Hypothesis 4, multiple regression analyses were conducted on the posterior food-safety beliefs, with posterior estimates of scientific consensus, evaluation condition, and their interaction as predictors and initial food-safety 
beliefs, issue familiarity, and personal importance as covariates. The predictors and covariates were mean-centered.

\section{Results}

\section{Preliminary Analyses}

Prior to examining the hypotheses, I verified whether the random assignment of participants to the evaluation conditions resulted in comparable groups. Table 1 shows the mean ratings of issue familiarity and personal importance, the mean initial estimates of scientific consensus, and the mean scores for initial food-safety beliefs per issue and condition. Multivariate analyses of variance (MANOVAs) with these measures as dependent variables and evaluation condition as a between-participant variable were conducted separately for the two issues. Regardless of issue, the assumptions of homogeneity were tenable, Box's $\boldsymbol{M}$ s $<11, \boldsymbol{F}$ s $<1$. No significant differences were found between the two evaluation conditions, Pillai's traces $<.01, \boldsymbol{F}_{\mathrm{S}}<1, \eta_{\mathbf{p}}{ }^{2} \mathrm{~s}<.01$.

Additionally, participants' reasons for evaluation were analyzed to confirm whether the manner of dealing with the scientific consensus message was manipulated successfully. On average, participants in the presentation-style evaluation condition produced 1.61 style-based reasons $(S D=1.05)$, whereas participants in the content evaluation condition produced no style-based reasons. Participants in the content evaluation condition produced more content-based reasons $(M=$ $1.49, S D=.78)$ than participants in the presentation-style evaluation condition $(M=.48, S D=.77), t(224)=9.79, p<.001$, $d=1.30$.

Finally, the effects of the evaluation condition on memory for the presented levels of scientific consensus were examined. The accuracy of recalled scientific consensus information was assessed by computing the absolute difference between the actual and recalled percentages of the responding scientists agreeing with the safety of foods grown with pesticides and GM foods. There were no significant differences in recall accuracy between the presentation-style and content evaluation conditions for the safety of foods with pesticides
$(M=2.05, M d n=.00$ and $M=2.13, M d n=.00$, respectively), Mann-Whitney $U=6087.5, d=0.08$, or GM foods $(M=2.93$, $M d n=.00$ and $M=2.43, M d n=.00$, respectively), MannWhitney $U=6102.5, d=0.08$.

\section{Posterior Perceptions of Scientific Consensus}

In line with Hypothesis 1, the posterior estimates of scientific consensus on the safety of foods grown with pesticides $(M=$ $63.41, S D=12.14)$ and GM foods $(M=78.75, S D=15.65)$ were higher than the initial estimates $(M=37.81, S D=$ 23.13 , and, $M=46.40, S D=23.23$, respectively), $t(225)=$ $16.75, p<.001, d=1.11$, and $t(225)=20.54, p<.001, d=$ 1.37 , respectively (also see the Electronic supplementary material A for the results of analyses conducted separately for the presentation-style and content evaluation conditions).

Results of the regression analyses on the posterior estimates of scientific consensus are presented in Table 2 (for correlations among the variables, see the Electronic supplementary material B). The evaluation condition was a significant or marginally significant predictor of the posterior estimates of scientific consensus on the safety of foods grown with pesticides, $\beta=-.14, \boldsymbol{p}<.05, \boldsymbol{f}^{2}=0.03$ (Model A1 in Table 2), and GM foods, $\beta=-.12, \boldsymbol{p}<.1, \boldsymbol{f}^{2}=0.02$ (Model $\mathrm{B} 1$ ), indicating that the levels of posteriorly perceived scientific consensus were higher for the presentation-style evaluation condition than for the content evaluation condition. Thus, Hypothesis 2 is supported. The initial food-safety beliefs $\times$ evaluation condition interaction was not significant for the safety of foods grown with pesticides, $\beta=.08, \boldsymbol{f}^{2}=0.01$ (Model A2), but significant for the safety of GM foods, $\beta=.15, \boldsymbol{p}<.05, \boldsymbol{f}^{2}=0.03$ (Model B2). The decomposition of the latter interaction revealed that the simple slopes defining the effect of initial food-safety beliefs were significantly greater than zero for the content evaluation condition, $\boldsymbol{b}=3.08$, $\boldsymbol{S E}=1.32, \boldsymbol{p}<.05$, but did not differ from zero for the presentation-style evaluation condition, $\boldsymbol{b}=-.66, \boldsymbol{S E}=1.32$. That is, only for the safety of GM foods, participants with stronger initial beliefs estimated the level of scientific consensus to be higher after they evaluated the message content but
Table 1 Means and Standard Deviations in Parentheses for Issue Familiarity, Personal Importance, Initial Estimates of Scientific. Consensus, and Initial Food-Safety Beliefs as a Function of Issue and Evaluation Condition

\begin{tabular}{|c|c|c|c|c|}
\hline \multirow[b]{2}{*}{ Measure } & \multicolumn{2}{|c|}{ Foods grown with pesticides } & \multicolumn{2}{|l|}{ GM foods } \\
\hline & $\begin{array}{l}\text { Presentation- } \\
\text { style }\end{array}$ & Content & $\begin{array}{l}\text { Presentation- } \\
\text { style }\end{array}$ & Content \\
\hline Issue familiarity & $3.35(1.34)$ & $3.18(1.47)$ & $2.69(1.34)$ & $2.62(1.30)$ \\
\hline Personal importance & $5.49(1.30)$ & $5.45(1.32)$ & $5.12(1.41)$ & $5.06(1.37)$ \\
\hline $\begin{array}{l}\text { Initial estimates of scientific } \\
\text { consensus }\end{array}$ & $38.40(23.30)$ & $\begin{array}{l}37.22 \\
\quad(23.05)\end{array}$ & $44.46(21.62)$ & $\begin{array}{l}48.34 \\
\quad(24.68)\end{array}$ \\
\hline Initial food-safety beliefs & $3.30(1.11)$ & $3.17(1.05)$ & $3.70(1.22)$ & $3.82(1.26)$ \\
\hline
\end{tabular}


Table 2 Results of Multiple Regression Analyses on Posterior Estimates of Scientific Consensus

\begin{tabular}{|c|c|c|c|c|c|c|}
\hline \multirow[b]{2}{*}{ Variable } & \multicolumn{3}{|c|}{ Foods grown with pesticides } & \multicolumn{3}{|c|}{ GM foods } \\
\hline & $\begin{array}{l}\text { Model } \\
\text { A1 }\end{array}$ & $\begin{array}{l}\text { Model } \\
\text { A2 }\end{array}$ & $\begin{array}{l}\text { Model } \\
\text { A3 }\end{array}$ & $\begin{array}{l}\text { Model } \\
\text { B1 }\end{array}$ & $\begin{array}{l}\text { Model } \\
\text { B2 }\end{array}$ & $\begin{array}{l}\text { Model } \\
\text { B3 }\end{array}$ \\
\hline Initial food-safety beliefs (A) & $.15^{\dagger}$ & $.16^{\dagger}$ & $.16^{*}$ & .10 & .10 & .10 \\
\hline Evaluation condition (B) & $-.14^{*}$ & $-.14^{*}$ & $-.14^{*}$ & $-.12^{\dagger}$ & $-.12^{\dagger}$ & $-.12^{\dagger}$ \\
\hline $\begin{array}{l}\text { Initial estimates of scientific } \\
\text { consensus }\end{array}$ & $.15^{\dagger}$ & $.15^{\dagger}$ & $.13^{\dagger}$ & $.26^{* *}$ & $.26^{* *}$ & $.26^{* *}$ \\
\hline Issue familiarity $(\mathrm{C})$ & $-.16^{*}$ & $-.16^{*}$ & $-.15^{*}$ & -.07 & -.08 & -.07 \\
\hline Personal importance & -.03 & -.03 & -.03 & -.05 & -.04 & -.05 \\
\hline $\mathrm{A} \times \mathrm{B}$ & - & .08 & - & - & $.15^{*}$ & - \\
\hline $\mathrm{C} \times \mathrm{B}$ & - & - & $-.15^{*}$ & - & - & .02 \\
\hline$R^{2}$ & $.15^{* * * *}$ & $.15^{* * * *}$ & $.17^{* * * *}$ & $.13^{* * *}$ & $.15^{* * *}$ & $.13^{* * *}$ \\
\hline
\end{tabular}

Note. Standardized regression coefficients are reported

${ }^{\dagger} p<.1 .^{*} p<.05 .^{* * *} p<.01 .^{* * * *} p<.001$ not after they evaluated the presentation style and manner. These results support Hypothesis 3 partly.

\section{Posterior Food-Safety Beliefs}

Participants' beliefs about the safety of foods grown with pesticides and GM foods became stronger after they received the scientific consensus message $(M=4.09, S D=1.17$ and $M=$ $4.55, S D=1.24$, respectively) than before $(M=3.23, S D=$ 1.08 and $M=3.76, S D=1.24$, respectively), $t(225)=12.64$, $p<.001, d=0.84$, and $t(225)=11.08, p<.001, d=0.74$, respectively.

Results of the regression analyses on the posterior foodsafety beliefs are presented in Table 3 (for correlations among the variables, see the Electronic supplementary material B). The posterior estimates of scientific consensus significantly predicted the posterior beliefs about the safety of foods grown with pesticides, $\beta=.25, \boldsymbol{p}<.001, \boldsymbol{f}^{2}=0.10$ (Model C1 in Table 3), and GM foods, $\beta=.35, \boldsymbol{p}<.001, \boldsymbol{f}^{2}=$
0.23 (Model D1). Contrary to Hypothesis 4, the posterior estimates $\times$ evaluation condition interaction was not significant for the safety of foods grown with pesticides, $\beta=.02, \boldsymbol{f}^{2}<0.01$ (Model C2), or GM foods, $\beta=-.02, \boldsymbol{f}^{2}<$ 0.01 (Model D2).

\section{Discussion}

The present study provided evidence that individuals' perceptions of scientific consensus is influenced by not only whether they receive a scientific consensus message but also how they deal with the given message. Consistent with the findings of prior research on scientific consensus messaging (e.g., Lewandowsky et al., 2013; Myers et al., 2015; van der Linden et al., 2019), it was found that informing participants about the levels of scientific consensus improved their perceptions of scientific consensus. More importantly, participants in the presentation-style evaluation condition - those who were
Table 3 Results of Multiple Regression Analyses on Posterior Food-Safety Beliefs

\begin{tabular}{|c|c|c|c|c|}
\hline \multirow[b]{2}{*}{ Variable } & \multicolumn{2}{|c|}{ Foods grown with pesticides } & \multicolumn{2}{|l|}{ GM foods } \\
\hline & Model C1 & Model C2 & Model D1 & Model D2 \\
\hline Posterior estimates of scientific consensus (A) & $.26^{* * *}$ & $.25^{* * * *}$ & $.35^{* * * *}$ & $.35^{* * * *}$ \\
\hline Evaluation condition (B) & -.00 & -.00 & -.04 & -.04 \\
\hline Initial food-safety beliefs & $.48^{* * *}$ & $.48^{* * *}$ & $.48^{* * * *}$ & $.49^{* * *}$ \\
\hline Issue familiarity & -.04 & -.03 & $-.09^{\dagger}$ & $-.09^{\dagger}$ \\
\hline Personal importance & $-.11^{*}$ & $-.11^{*}$ & $-.11^{*}$ & $-.11^{*}$ \\
\hline $\mathrm{A} \times \mathrm{B}$ & - & .02 & - & -.02 \\
\hline$R^{2}$ & $.43^{* * *}$ & $.43^{* * *}$ & $.53^{* * *}$ & $.53^{* * *}$ \\
\hline
\end{tabular}

Note. Standardized regression coefficients are reported ${ }^{\dagger} p<.1 .^{*} p<.05 .{ }^{* * * *} p<.001$ 
encouraged to heuristically process the information about scientific consensus in the message - estimated the levels of scientific consensus to be higher than participants in the content evaluation condition - those who could process the information systematically. This finding supports the idea that the heuristic processing of scientific consensus information enhances the impact of scientific consensus messaging on perceived scientific consensus compared with systematic processing.

It was also found that participants' initial beliefs about the safety of GM foods influenced their posterior perceptions of scientific consensus for the content evaluation condition but not for the presentation-style evaluation condition. Only when participants could systematically process the information about scientific consensus in the message, those who more strongly believed GM foods to be unsafe were more likely to resist changing their perceptions of scientific consensus on the issue. This result is in line with Giner-Sorolla and Chaiken (1997), who found that exposure to group consensus information incompatible with one's vested interests stimulated the systematic and defensive processing of the information, and extend their findings to cases where scientific consensus information is processed. In the present study, by facing up to the survey results indicating the relatively high level of scientific consensus on the safety of GM foods, those who were more skeptical about the safety of GM foods may have been more highly motivated to scrutinize the survey results carefully. Besides, the scientific consensus message did not include any arguments supporting or opposing the survey results. This feature of the message may have induced the motivated participants to deal with the survey results, consulting their preexisting beliefs.

Unexpectedly, for the safety of foods grown with pesticides, the content versus presentation-style evaluation conditions had no significant moderation effect on the influence of participants' initial beliefs. Given that potential information resources for systematic processing are not confined to a given message or issue-relevant beliefs (e.g., Chaiken \& Ledgerwood, 2012), one possible reason for the null moderation effect is that participants may have had some issuerelevant knowledge that stimulated and was usable for the systematic processing of the scientific consensus information. Supporting this interpretation, participants' self-reported familiarity with the health risks of foods grown with pesticides $(M=3.26, S D=1.40)$ was higher than that with the health risks of GM foods $(M=2.65, S D=1.32), t(225)=7.07$, $p<.001, d=0.47$. Furthermore, additional multiple regression analyses, in which issue familiarity $\times$ evaluation condition interaction was added as a predictor variable to the regression models A1 and B1, revealed that only for the safety of foods grown with pesticides, the interaction significantly predicted the posterior estimates of scientific consensus, $\beta=-.15$, $\boldsymbol{p}<.05, \boldsymbol{f}^{2}=0.03$ (see Models A3 and B3 in Table 2). The simple slopes defining the effect of issue familiarity were significantly smaller than zero for the content evaluation condition, $b=-2.61, S E=.75, p<.001$, but did not differ from zero for the presentation-style evaluation condition, $b=-.03$, $S E=81$. That is, those who were more familiar with the health risks of foods grown with pesticides estimated the level of scientific consensus to be lower only after they evaluated the message content.

Regardless of issue, informing participants about the level of scientific consensus effectively changed their food-safety beliefs as well. Additionally, participants' posterior perceptions of scientific consensus were a predictor of their posterior food-safety beliefs. However, the content versus presentationstyle evaluation conditions did not significantly moderate the predicting effects of posteriorly perceived scientific consensus. Considering that the evaluation condition had only a small impact on participants' posterior perceptions of scientific consensus $\left(\boldsymbol{f}^{2} \mathrm{~S}=0.02\right.$ and 0.03$)$, a likely explanation is that our experimental manipulation may not have been so powerful in differentially stimulating heuristic and systematic processing, and therefore, the differential effects of the content versus presentation-style evaluation may not have extended to their posterior food-safety beliefs. Alternatively, as suggested in the study by Deryugina and Shurchkov (2016), scientific consensus messaging may have changed participants' foodsafety beliefs, at least for a while, whether they accepted the message content superficially or not. If so, a follow-up would have enabled us to detect the moderation effects of content versus presentation-style evaluation. Unfortunately, examining the two possibilities is beyond the present study's capabilities now and requires further investigation.

\section{Practical Implications and Limitations}

The findings of the present study have practical implications. First of all, the present results highlight the potential importance of processing mode. The impact of scientific consensus messaging on people's perceptions of scientific consensus may differ according to whether they process information about scientific consensus heuristically or systematically. Additionally, at least under certain conditions, those who engage in the systematic mode may deal with a scientific consensus message in defense of their preexisting scientific beliefs. To effectively communicate the actual scientific consensus, practitioners should consider these possibilities. Second, although the main focus of research on scientific consensus messaging has been on the effectiveness of communicating a high level of scientific consensus (e.g., Dixon, 2016; Myers et al., 2015), the present study found that the message about $68 \%$ scientific consensus, as well as $88 \%$ scientific consensus, considerably improved participants' perceptions of scientific consensus and changed their scientific beliefs. People may 
benefit from being informed about the actual level of scientific consensus even when the level is not so high. Finally, regardless of evaluation condition, the posterior estimates of scientific consensus were found to predict the posterior food-safety beliefs. In line with the idea that perceived scientific consensus plays a key role in fostering scientifically valid beliefs (van der Linden et al., 2015), this finding implies that improving people's perceptions of scientific consensus may be one efficient way to change their scientific beliefs.

Despite these implications, several limitations should be considered. The first limitation concerns the external validity of the presentation-style and content evaluation conditions. In the present study, the two conditions were artificially created to examine the impact of scientific consensus messaging from the perspectives of heuristic and systematic processing. Accordingly, we do not know whether people spontaneously engage in each mode of processing when they receive a scientific consensus message in real-world situations, and if so, what factors affect their processing mode. Future work should address these issues. Second, the present study did not directly measure how participants processed the information about scientific consensus in the message. The presentation-style and content evaluation instructions produced differential effects on their manner of dealing with the scientific consensus message. Nevertheless, whether this manipulation led to heuristic and systematic processing remain untested. To closely examine psychological mechanism underlying the impact of scientific consensus messaging, subsequent studies should employ process measures, such as thought-listing (e.g., Giner-Sorolla \& Chaiken, 1997). Third, the two scientific issues adopted in the present study differed in some respects, such as the self-reported familiarity, the level of scientific consensus presented in the message, and the initially perceived level of scientific consensus. Therefore, it is difficult to definitely determine the cause of the observed differences in the impact of scientific consensus messaging between the two issues. Future research might experimentally manipulate those variables and explore their influence. Finally, the present study focused on a sample of Japanese undergraduates and the issues of food safety. It would be important to confirm and extend the present findings by including more diverse samples and issues.

Supplementary Information The online version contains supplementary material available at https://doi.org/10.1007/s12144-020-01275-1.

Data Availability The data that support the findings of this study are available from the corresponding author.

\section{Compliance with Ethical Standards}

Conflict of Interest There is no conflict of interest.
Ethical Approval All of the procedures performed in the present study were in accordance with the APA and JPA (the Japanese Psychological Association) ethical standards.

Informed Consent Informed consent was obtained from all individual participants included in the study.

Open Access This article is licensed under a Creative Commons Attribution 4.0 International License, which permits use, sharing, adaptation, distribution and reproduction in any medium or format, as long as you give appropriate credit to the original author(s) and the source, provide a link to the Creative Commons licence, and indicate if changes were made. The images or other third party material in this article are included in the article's Creative Commons licence, unless indicated otherwise in a credit line to the material. If material is not included in the article's Creative Commons licence and your intended use is not permitted by statutory regulation or exceeds the permitted use, you will need to obtain permission directly from the copyright holder. To view a copy of this licence, visit http://creativecommons.org/licenses/by/4.0/.

\section{References}

Bahník, S., Englich, B., \& Strack, F. (2017). Anchoring effect. In M. Englich \& T. Mussweiler (Eds.), Cognitive illusions: Intriguing phenomena in judgement, thinking and memory (pp. 223-241). London: Routledge.

Bohner, G., Erb, H.-P., \& Siebler, F. (2008). Information processing approaches to persuasion: Integrating assumptions from the dualand single-processing perspectives. In W. D. Crano \& R. Prislin (Eds.), Attitudes and attitude change (pp. 161-188). New York, NY: Psychology Press.

Bolsen, T., \& Druckman, J. N. (2018). Do partisanship and politicization undermine the impact of a scientific consensus message about climate change? Group Processes \& Intergroup Relations, 21(3), 389402. https://doi.org/10.1177/1368430217737855.

Chaiken, S. (1980). Heuristic and systematic information processing and the use of source versus message cues in persuasion. Journal of Personality and Social Psychology, 39(5), 752-766. https://doi. org/10.1037/0022-3514.39.5.752.

Chaiken, S., \& Ledgerwood, A. (2012). A theory of heuristic and systematic information processing. In P. A. M. van Lange, A. W. Kruglanski, \& E. T. Higgins (Eds.), Handbook of theories of social psychology (pp. 246-266). Thousand Oaks, CA: Sage.

Chen, S., \& Chaiken, S. (1999). The heuristic-systematic model in its broader context. In S. Chaiken \& Y. Trope (Eds.), Dual-process theories in social psychology (pp. 73-96). New York, NY: Guilford Press.

Conway III, L. G., \& Repke, M. A. (2019). The psychological contamination of pro-environmental consensus: Political pressure for environmental belief agreement undermines its long-term power. Journal of Environmental Psychology, 62, 12-21. https://doi.org/ 10.1016/j.jenvp.2019.02.001.

Cook, J., \& Lewandowsky, S. (2016). Rational irrationality: Modeling climate change belief polarization using Bayesian networks. Topics in Cognitive Science, 8(1), 160-179. https://doi.org/10.1111/tops. 12186.

Craik, F. I. M., \& Lockhart, R. S. (1972). Levels of processing: A framework for memory research. Journal of Verbal Learning and Verbal Behavior, 11(6), 671-684. https://doi.org/10.1016/S0022-5371(72) 80001-X. 
Darke, P. R., Chaiken, S., Bohner, G., Einwiller, S., Erb, H.-P., \& Hazlewood, J. D. (1998). Accuracy motivation, consensus information, and the law of large numbers: Effects on attitude judgment in the absence of argumentation. Personality and Social Psychology Bulletin, 24(11), 1205-1215. https://doi.org/10.1177/ 01461672982411007.

Deryugina, T., \& Shurchkov, O. (2016). The effect of information provision on public consensus about climate change. PLoS One, 11(4), e0151469. https://doi.org/10.1371/journal.pone.0151469.

Ding, D., Maibach, E. W., Zhao, X., Roser-Renouf, C., \& Leiserowitz, A. (2011). Support for climate policy and societal action are linked to perceptions about scientific agreement. Nature Climate Change, 1(9), 462-466. https://doi.org/10.1038/NCLIMATE1295.

Dixon, G. (2016). Applying the gateway belief model to genetically modified food perceptions: New insights and additional questions. Journal of Communication, 66(6), 888-908. https://doi.org/10. 1111/jcom.12260.

Faul, F., Erdfelder, E., Buchner, A., \& Lang, A.-G. (2009). Statistical power analyses using $\mathrm{G}^{*}$ power 3.1 : Tests for correlation and regression analyses. Behavior Research Methods, 41(4), 1149-1160. https://doi.org/10.3758/BRM.41.4.1149.

Food Safety Commission of Japan (2015). Syokuhin ni kakawaru risukuninshiki-ankeito-chousa no kekka nitsuite [Public views on food risk]. Retrieved from https://www.fsc.go.jp/osirase/risk_ questionnaire_20150513.pdf

Giner-Sorolla, R., \& Chaiken, S. (1997). Selective use of heuristic and systematic processing under defense motivation. Personality and Social Psychology Bulletin, 23(1), 84-97. https://doi.org/10.1177/ 0146167297231009.

Goldberg, M. H., van der Linden, S., Ballew, M. T., Rosenthal, S. A., \& Leiserowitz, A. (2019). The role of anchoring in judgments about expert consensus. Journal of Applied Social Psychology, 49(3), 192-200. https://doi.org/10.1111/jasp.12576.

Griffin, R. J., Neuwirth, K., Giese, J., \& Dunwoody, S. (2002). Linking the heuristic-systematic model and depth of processing. Communication Research, 29(6), 705-732. https://doi.org/10. 1177/009365002237833.

Harris, A. J. L., Sildmäe, O., Speekenbrink, M., \& Hahn, U. (2019). The potential power of experience in communications of expert consensus levels. Journal of Risk Research, 22(5), 593-609. https://doi. org/10.1080/13669877.2018.1440416.

Kahan, D. M. (2015). Climate-science communication and the measurement problem. Advances in Political Psychology, 36(Suppl), 1-43. https://doi.org/10.1111/pops.12244.

Kahan, D. M., Jenkins-Smith, H., \& Braman, D. (2011). Cultural cognition of scientific consensus. Journal of Risk Research, 14(2), 147174. https://doi.org/10.1080/13669877.2010.511246.
Kerr, J. R., \& Wilson, M. S. (2018). Changes in perceived scientific consensus shift beliefs about climate change and GM food safety. PLoS One, 13(7), e0200295. https://doi.org/10.1371/journal.pone. 0200295.

Kobayashi, K. (2018). The impact of perceived scientific and social consensus on scientific beliefs. Science Communication, 40(1), 63-88. https://doi.org/10.1177/1075547017748948.

Kobayashi, K. (2019). Communicating highly divergent levels of scientific and social consensus: Its effects on people's scientific beliefs. Social Influence, 14(3-4), 65-76. https://doi.org/10.1080/ 15534510.2019 .1650105 .

Lewandowsky, S., Gignac, G. E., \& Vaughan, S. (2013). The pivotal role of perceived scientific consensus in acceptance of science. Nature Climate Change, 3(4), 399-404. https://doi.org/10.1038/ NCLIMATE1720.

Mackie, D. M. (1987). Systematic and nonsystematic processing of majority and minority persuasive communications. Journal of Personality and Social Psychology, 53(1), 41-52. https://doi.org/ 10.1037/0022-3514.53.1.41.

Martin, R., Hewstone, M., \& Martin, P. Y. (2007). Systematic and heuristic processing of majority- and minority-endorsed messages: The effects of varying outcome relevance and levels of orientation on attitude and message processing. Personality and Social Psychology Bulletin, 33(1), 43-56. https://doi.org/10.1177/0146167206294251.

Myers, T. A., Maibach, E., Peters, E., \& Leiserowitz, A. (2015). Simple messages help set the record straight about scientific agreement on human-caused climate change: The results of two experiments. PLoS One, 10(3), e0120985. https://doi.org/10.1371/journal.pone. 0120985.

Pew Research Center (2015). Public and scientists' views on science and society. Retrieved from http://www.pewinternet.org/2015/01/29/ public-and-scientists-views-on-science-and-society/

Van der Linden, S. L., Leiserowitz, A. A., Feinberg, G. D., \& Maibach, E. W. (2015). The scientific consensus on climate change as a gateway belief: Experimental evidence. PLoS One, 10(2), e0118489. https:// doi.org/10.1371/journal.pone.0118489.

Van der Linden, S., Leiserowitz, A., Rosenthal, S., \& Maibach, E. (2017). Inoculating the public against misinformation about climate change. Global Challenges, 1(2), 1600008. https://doi.org/10.1002/gch2. 201600008.

Van der Linden, S., Leiserowitz, A., \& Maibach, E. W. (2019). The gateway belief model: A large-scale replication. Journal of Environmental Psychology, 62, 49-58. https://doi.org/10.1016/j. jenvp.2019.01.009.

Publisher's Note Springer Nature remains neutral with regard to jurisdictional claims in published maps and institutional affiliations. 